\title{
Genetic Algorithm Aided Antenna Placement in 3D and Parameter Determination Considering Electromagnetic Field Pollution Constraints
}

\author{
Tomislav Rolich and Darko Grundler \\ Faculty of Textile Technology, University of Zagreb, Croatia
}

\begin{abstract}
This paper presents genetic algorithm based method for antenna placement in 3D space and parameter determination satisfying environmental electromagnetic field pollution constraints. The main goal is to find out antenna parameters (power, position in $3 \mathrm{D}$, azimuth and elevation) in the area of interest so that electromagnetic field satisfies minimal electromagnetic field strength for service availability and, at the same time, be below prescribed limit in restricted subareas (people populated areas). The proposed method is validated with two real world antenna types and with seven different terrain configurations (various restricted areas). Besides finding the most optimal antenna parameters, the method finds "almost" optimal solutions which give certain freedom to choose alternative antenna position if optimal is not available. The investigation described here is extension of previous $2 \mathrm{D}$ research.
\end{abstract}

Keywords: electromagnetic radiation, transmitter, genetic algorithms, MATLAB, optimization

\section{Introduction}

Many of the problems found in telecommunications can be formulated as optimization tasks. Some examples are assigning frequencies in radio link communications, developing error correcting codes for transmission of messages, and designing the telecommunication network. In practice, most of these optimization tasks are unaffordable with exact techniques. In this sense, Evolutionary Algorithms have constituted a popular choice [1].
Radio network design is a fundamental problem in cellular networks for telecommunications. In these networks, the terrain must be covered by a set of base stations (or antennae), each of which defines a covered area called cell. The problem may be reduced to figure out the optimal placement of antennae out of a list of candidate sites, trying to satisfy two objectives: to maximize the area covered by the radio signal and to reduce the number of used antennae $[2,3,4,5]$. In this paper we were solving a similar task, but yet a different one.

Excessive electromagnetic fields which can be dangerous to people is of increased concern because of exposition of living organisms to more and more sources of electromagnetic fields (radio, TV, GSM, WiFi, etc.). Determination of various antenna parameters (power, position in $3 \mathrm{D}$, azimuth and elevation) is difficult because there is a complex interaction of various sources of electromagnetic fields and specific area configuration (residential areas). In previous papers, the authors investigated the problem with uniform and nonuniform transmitter radiation diagram in $2 \mathrm{D}[6,7,8]$ and with uniform transmitter radiation diagram in 3D [9] to find out suitable antenna placement optimization method. Based upon promising results $[6,7,8,9]$, the authors here use genetic algorithm to optimize electromagnetic field distribution in 3D space for antenna with real-world spatial radiation diagram. There are six vari- 
able antenna parameters: radiation power, position in 3D $(x, y$ and $z)$, azimuth and elevation. The constraints are minimum electromagnetic field strength (minimum service availability) in the whole area of interest and, at the same time, maximum allowable electromagnetic field strength (health hazard) in the restricted subareas (buildings or other populated areas). In this paper, two types of antennas are used and the results are presented.

\section{Investigations}

Presumptions in the investigations described here were that the area of interest is a space dimension of $200 \mathrm{~m} \times 200 \mathrm{~m} \times 40 \mathrm{~m}$ (width $x$ length $x$ height) and that the transmitter has to be positioned within this space. Inside that space, different shapes of restricted subareas are defined. Restricted subareas are the areas where humans permanently or often reside (e.g. buildings) and wich are subject to electromagnetic pollution health hazard. It is assumed that restricted areas are transparent regarding electromagnetic field propagation.

Electromagnetic field is calculated for uniformly distributed points in this space. Calculated points are evenly distributed in the space and the distance between adjacent calculated points in $x, y$ and $z$ axis direction is $1 \mathrm{~m}$. This means that there are $200^{2} \times 40=1,600,000$ observed points for which electromagnetic field strength is calculated. Transmitter antenna can be positioned only in the limited range horizontally: $20 \mathrm{~m} \leq x_{0} \leq 180 \mathrm{~m}, 20 \mathrm{~m} \leq y_{0} \leq 180 \mathrm{~m}$ and vertically: $10 \mathrm{~m} \leq z_{0} \leq 30 \mathrm{~m}$. The direction of antenna can be positioned also only in the limited range for azimuth: $0^{\circ} \leq \varphi \leq 360^{\circ}$ and for elevation: $-30^{\circ} \leq \vartheta \leq 30^{\circ}$. The goal is to find optimal antenna position, its direction in the space and its power, to satisfy electromagnetic field constraints in the restricted subareas and, at the same time, to satisfy the reception level of electromagnetic field in the whole area. Electromagnetic field has to be lower than prescribed pollution health hazard limit in restricted subareas and it has to be above prescribed reception limit in the whole observed area $(200 \mathrm{~m} \times$ $200 \mathrm{~m} \times 40 \mathrm{~m}$ ).
Strength of the electromagnetic field can be calculated according to $[10]$ :

$$
E=\frac{5.5 \cdot \sqrt{E I R P}}{d} \cdot F(\varphi, \vartheta)
$$

where:

$E I R P=E R P+2.15-$ effectively isotropic radiated power,

$E R P$ - effectively isotropic radiated power in respect to half wavelength dipole (in the investigations described here, $E R P$ is limited to $5 d b W \leq E R P \leq 35 d b W)$,

$F(\varphi, \vartheta)$-damping factor of electric field which is a function of deflection angles from direction of maximum in azimuth $\varphi$ and elevation $\vartheta$,

$d$-distance from the antenna.

In this investigation a damping factor is a horizontal and a vertical radiation diagrams of an antenna with a nonuniform radiation. Antenna manufacturers usually supply the numerical data of the damping factor for the step of one degree from $0^{\circ}$ to $360^{\circ}$ in two perpendicular planes. From these numerical data of a damping factor, mathematical functions which best fit the numerical data for each plane have been set up.

In this investigation, one type of antenna with two configurations has been chosen: K752921 (450 MHz, M=80, D=25; further in the paper it will be referred to as antenna 1) and K752921 (450 MHz, $M=100, D=50$; further in the paper it will be referred to as antenna 2) [11]. Based on the horizontal and vertical radiation diagrams, the following mathematical function has been chosen to analytically represent a damping factor:

$$
\begin{aligned}
& f_{h}(\varphi)=\sum_{i=0}^{6} a_{i} \cdot \cos \left[i \cdot\left(\varphi+\varphi_{0}\right)\right] \\
& f_{v}(\vartheta)=\sum_{i=0}^{6} a_{i} \cdot \cos \left[i \cdot\left(\vartheta+\vartheta_{0}\right)\right]
\end{aligned}
$$

Parameters from $a_{0}$ to $a_{6}$ of the above functions have been determined using program MATLAB and Optimization Toolbox [12]. For this purpose, a function lsqcurvefit from Optimization Toolbox has been used for solving a nonlinear curve-fitting (data-fitting) problem in the 
least-squares sense with the method of preconditioned conjugate gradients. These functions approximate the numerical data of a damping factor. Determined parameters for horizontal radiation diagram for type of antenna 1 are: $a_{0}=0.7317, a_{1}=0.3595, a_{2}=-0.0709$, $a_{3}=-0.0375, a_{4}=0.0142, a_{5}=-0.0025$ and $a_{6}=0.0009$ and for type of antenna 2 they are: $a_{0}=0.6522, a_{1}=0.0150, a_{2}=-0.2778$, $a_{3}=0.0398, a_{4}=0.0729, a_{5}=-0.0046$ and $a_{6}=0.0066$. Determined parameters for ver-

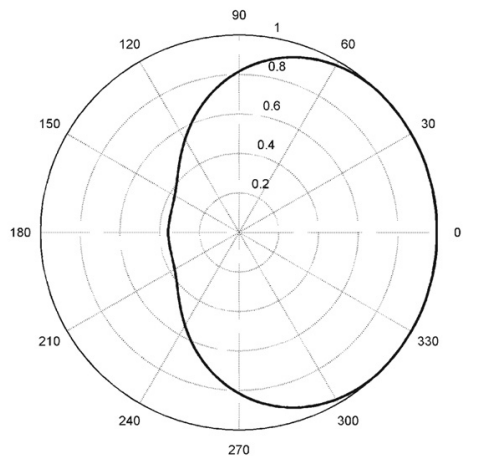

a. horizontal radiation diagram tical radiation diagram for type of antenna 1 are: $a_{0}=0.3964, a_{1}=0.3004, a_{2}=0.2953$, $a_{3}=0.0167, a_{4}=-0.0337, a_{5}=0.0007$ and $a_{6}=0.0183$ and for type of antenna 2 they are: $a_{0}=0.5901, a_{1}=-0.0000, a_{2}=0.4395$, $a_{3}=-0.0000, a_{4}=-0.0501, a_{5}=-0.0000$ and $a_{6}=0.0271$.

Figure 1 shows the horizontal and the vertical radiation diagrams based on an analytical approximation of damping factor functions for antenna 1. Figure 2 shows the same data for antenna 2.

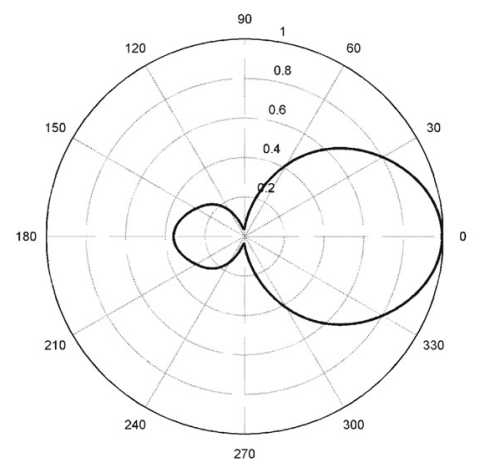

b. vertical radiation diagram

Figure 1. Horizontal and vertical radiation diagrams based on an analytical approximation of a damping factor functions for antenna 1 .

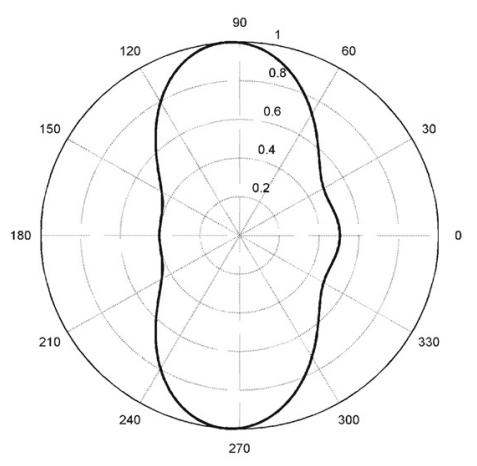

a. horizontal radiation diagram

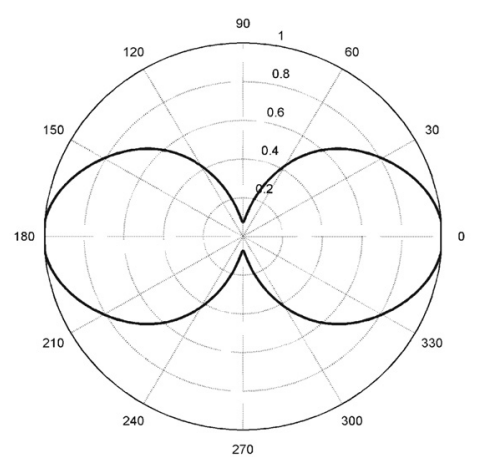

b. vertical radiation diagram

Figure 2. Horizontal and vertical radiation diagrams based on an analytical approximation of a damping factor functions for antenna 2 .

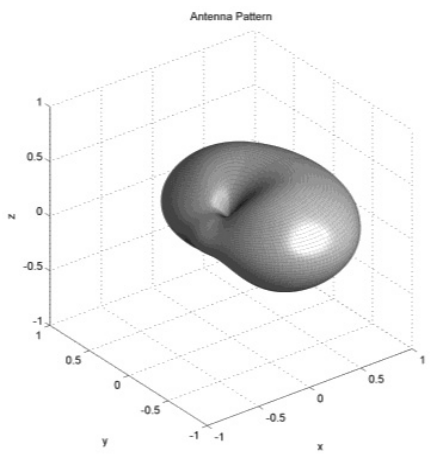

a.antenna 1

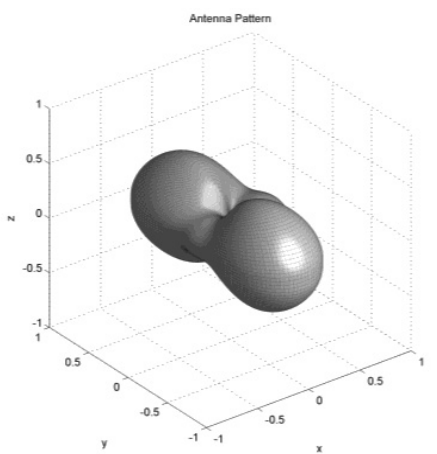

b. antenna 2

Figure 3. Spatial radiation diagrams for antenna 1 and for antenna 2. 
Spatial radiation diagram for both antenna configurations are approximated according to [13]:

$$
F(\varphi, \vartheta) \approx f_{h}(\varphi) \cdot f_{v}(\vartheta)
$$

Figure 3 shows spatial radiation diagrams for both antenna configurations based on equation (4).

Strength of the electromagnetic field in threedimensional space has been observed, so the equation for it is:

$$
E=\frac{5.5 \cdot \sqrt{E I R P}}{\sqrt{\left(x-x_{0}\right)^{2}+\left(y-y_{0}\right)^{2}+\left(z-z_{0}\right)^{2}}} \cdot F(\varphi, \vartheta)
$$

where:

$x_{0}, y_{0}$ and $z_{0}$ are coordinates of the transmitter location.

Optimal transmitter parameters (power, position, azimuth and elevation) have been determined using a genetic algorithm. Program MATLAB version 7.11.0.584 (R2010b) with Global Optimization Toolbox version 3.1 has been used for this purpose [14]. Fitness function which needs to be minimized is:

$$
f=\min (E)+\bar{E}+\overline{E_{k}}
$$

where:

$\min (E)$ - minimal total strength of the electromagnetic field in the whole observed area,

$\bar{E}$ - mean strength of the electromagnetic field in the whole observed area,

$\overline{E_{k}}-$ mean strength of the electromagnetic field in the restricted subareas.

Fitness function (6) is original and was obtained empirically (the authors tried several different fitness functions and decided that this one has the best features for investigated problem). Fitness function mentioned above has been used for genetic algorithm population's individuals which satisfied the criteria of maximal $\left(E_{\max }=10 \mathrm{~V} / \mathrm{m}\right.$, for restricted subareas $)$ and minimal $\left(E_{\min }=0.1 \mathrm{~V} / \mathrm{m}\right.$, for signal reception) strength of the electric field. If a GA individual did not satisfy these criteria then its fitness function was multiplied by penalty factor of 1000 .

Representation of an individual is a 6 components vector of real numbers:
$v=\left[\begin{array}{llllll}E R P & x_{0} & y_{0} & z_{0} & \varphi_{0} & \vartheta_{0}\end{array}\right]$. Genetic algorithm parameters are shown in Table 1. Parameters were obtained empirically (the authors tried a variety of parameter values and decided that these where the most suitable for investigated problem). In this paper the stochastic universal sampling is used as a selection procedure $[15,16,17]$. In each generation 4 individuals have been created with a crossover procedure, 4 individuals have been created with a mutation procedure, and 2 individuals are elite individuals (individuals with the lowest value of a fitness function from the last generation) in each of the three subpopulations.

\begin{tabular}{|c|c|}
\hline Parameter & Value / Property \\
\hline \hline Population size & $\begin{array}{c}30 \text { (3 subpopulations } \\
\text { of } 10 \text { individuals) }\end{array}$ \\
\hline Number of generation & 50 \\
\hline Selection & Stochastic uniform \\
\hline Crossover & Heuristic \\
\hline Mutation & Adaptive feasible \\
\hline Fitness scaling & Proportional \\
\hline Number of elite individuals & 2 \\
\hline Crossover fraction & 0.5 \\
\hline
\end{tabular}

Table 1. Genetic algorithm parameters in Global Optimization Toolbox.

\section{Results and Discussion}

To verify the method, seven cases with a different number, size and shape of restricted subareas were chosen (maximal strength of the electric field was $E_{\max }=10 \mathrm{~V} / \mathrm{m}$ and minimal strength of the electric field regarding signal covering was $\left.E_{\min }=0.1 \mathrm{~V} / \mathrm{m}\right)$. Procedure was performed separately for each type of antenna configurations. Optimization computation was performed on Microsoft Windows 7 (32-bits), MATLAB version 7.11.0.584 (R2010b) with Global Optimization Toolbox version 3.1. The computer used for this purpose was equipped with Intel Core 2 Duo E6600 $2.4 \mathrm{GHz}$ processor and with $3 \mathrm{~GB}$ of DDR2 $(800 \mathrm{MHz}) \mathrm{RAM}$. In Table 2 the best individuals from the last generation are presented for all seven restricted subarea configurations and for a minimal strength of the electric field $E_{\min }=0.1 \mathrm{~V} / \mathrm{m}$ for antenna 
1. Data represents transmitter power ERP, transmitter location $\left(x_{0}, y_{0}, z_{0}\right)$, horizontal direction (azimuth) $\varphi_{0}$, vertical direction (elevation) $\vartheta_{0}$ and fitness function value $f$. In Table 3 the same is presented for antenna 2 .

Duration of computation for optimization procedure for antenna 1 was between 171 and 173 minutes for cases from 1 to 7 , and for antenna 2 it was between 167 and 178 minutes.

In following figures example of some results are presented. Contour and values of strength of the electromagnetic field in the whole observed area for the best individual are presented for various cases of the restricted subareas configuration. In Figure 4, contour and values of strength of the electromagnetic field in the observed area for the best individual for the $5^{\text {th }}$ case of restricted subarea configuration for antenna 1 and for $0 \mathrm{~m}, 20 \mathrm{~m}$ and $40 \mathrm{~m}$ heights. In Figure 5, the same is shown for the best individual for the $7^{\text {th }}$ case of restricted subarea configuration. In Figure 6, contour and values of strength of the electromagnetic field in the observed area for the best individual for the $5^{\text {th }}$ case of restricted subarea configuration for antenna 2 and for $0 \mathrm{~m}$, $20 \mathrm{~m}$ and $40 \mathrm{~m}$ heights. In Figure 7, the same is shown for the best individual for the $6^{\text {th }}$ case of restricted subarea configuration.

In real world applications, available transmitter locations are restricted and it may not be possible to place transmitter on the positions determined by the best individual from a GA run. In such a case it is possible to choose one of the other "good" individuals from a GA run. This may not be the best set of transmitter parameters (a GA individual), but still good enough regarding initial conditions. Figure 8 shows examples of transmitter positions (a GA individuals from the last generation) for the $5^{\text {th }}$ and the $7^{\text {th }}$ cases of restricted subarea configuration for antenna 1, while Figure 9 shows those for the $5^{\text {th }}$ and the $6^{\text {th }}$ cases of restricted subarea configuration for antenna 2. Figures present observing area, restricted subareas and valid transmitter positions. Possible transmitter positions are marked with dark gray circles.

Figures 10 and 11 show examples of different spatial orientation of antennas 1 and 2 respectively. Figures also depict approximated spatial radiation diagrams for each antenna.

\begin{tabular}{|c|c|c|c|c|c|c|c|}
\hline Case & $\mathbf{E R P}(\mathbf{d b W})$ & $x_{0}(\mathbf{m})$ & $y_{0}(\mathbf{m})$ & $z_{0}(\mathbf{m})$ & $\varphi_{0}\left[{ }^{\circ}\right]$ & $\vartheta_{0}\left[{ }^{\circ}\right]$ & $\mathbf{f}$ \\
\hline \hline $1^{\text {st }}$ & 21,03 & 52,70 & 20,33 & 24,78 & 117,38 & $-21,15$ & 0,73 \\
\hline $2^{\text {nd }}$ & 19,65 & 101,09 & 177,68 & 21,65 & 243,32 & 19,60 & 0,90 \\
\hline $3^{\text {rd }}$ & 21,40 & 22,83 & 41,25 & 24,26 & 116,17 & $-26,21$ & 0,83 \\
\hline $4^{\text {th }}$ & 18,96 & 20,83 & 100,86 & 21,86 & 187,21 & 0,73 & 0,84 \\
\hline $5^{\text {th }}$ & 19,54 & 150,34 & 57,26 & 21,43 & 77,06 & 29,98 & 0,90 \\
\hline $6^{\text {th }}$ & 18,29 & 164,85 & 22,63 & 20,30 & 358,14 & 3,09 & 0,83 \\
\hline $7^{\text {th }}$ & 19,74 & 83,78 & 179,98 & 18,75 & 265,08 & $-22,09$ & 0,83 \\
\hline
\end{tabular}

Table 2. The best individuals from the last generation for a minimal strength of the electric field $E_{\min }=0.1 \mathrm{~V} / \mathrm{m}$ for antenna 1 .

\begin{tabular}{|c|c|c|c|c|c|c|c|}
\hline Case & ERP $(\mathbf{d b W})$ & $x_{0}(\mathbf{m})$ & $y_{0}(\mathbf{m})$ & $z_{0}(\mathbf{m})$ & $\varphi_{0}\left[{ }^{\circ}\right]$ & $\vartheta_{0}\left[^{\circ}\right]$ & $\mathbf{f}$ \\
\hline \hline $1^{\text {st }}$ & 22,11 & 179,34 & 27,21 & 14,96 & 265,74 & 28,11 & 1,02 \\
\hline $2^{\text {nd }}$ & 21,50 & 20,27 & 33,25 & 27,36 & 135,67 & 7,39 & 0,96 \\
\hline $3^{\text {rd }}$ & 20,60 & 39,00 & 179,73 & 21,82 & 210,36 & $-22,34$ & 0,85 \\
\hline $4^{\text {th }}$ & 19,95 & 163,51 & 45,72 & 21,64 & 77,77 & 24,37 & 1,05 \\
\hline $5^{\text {th }}$ & 20,62 & 24,13 & 142,41 & 23,48 & 359,72 & 24,91 & 1,03 \\
\hline $6^{\text {th }}$ & 20,77 & 21,57 & 118,53 & 14,17 & 181,29 & $-0,16$ & 1,10 \\
\hline $7^{\text {th }}$ & 19,38 & 26,48 & 24,69 & 18,61 & 288,46 & 12,98 & 0,90 \\
\hline
\end{tabular}

Table 3. The best individuals from the last generation for a minimal strength of the electric field $E_{\min }=0.1 \mathrm{~V} / \mathrm{m}$ for antenna 2. 

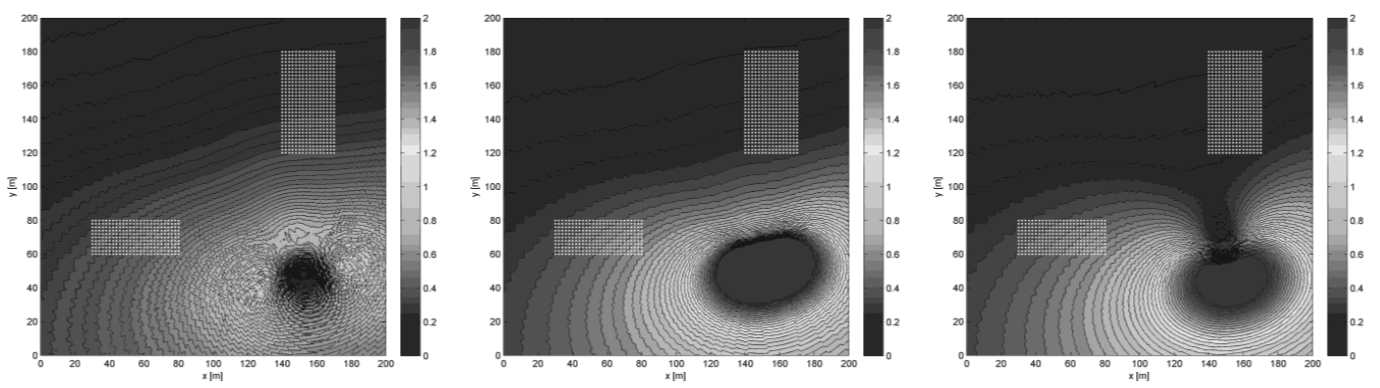
a. $\mathrm{z}=0 \mathrm{~m}$
b. $\mathrm{z}=20 \mathrm{~m}$
c. $\mathrm{z}=40 \mathrm{~m}$

Figure 4. Contour and values of strength of the electromagnetic field in the observed area for the best individual for the $5^{\text {th }}$ case of restricted subarea configuration, antenna 1 , for $0 \mathrm{~m}, 20 \mathrm{~m}$ and $40 \mathrm{~m}$ heights.
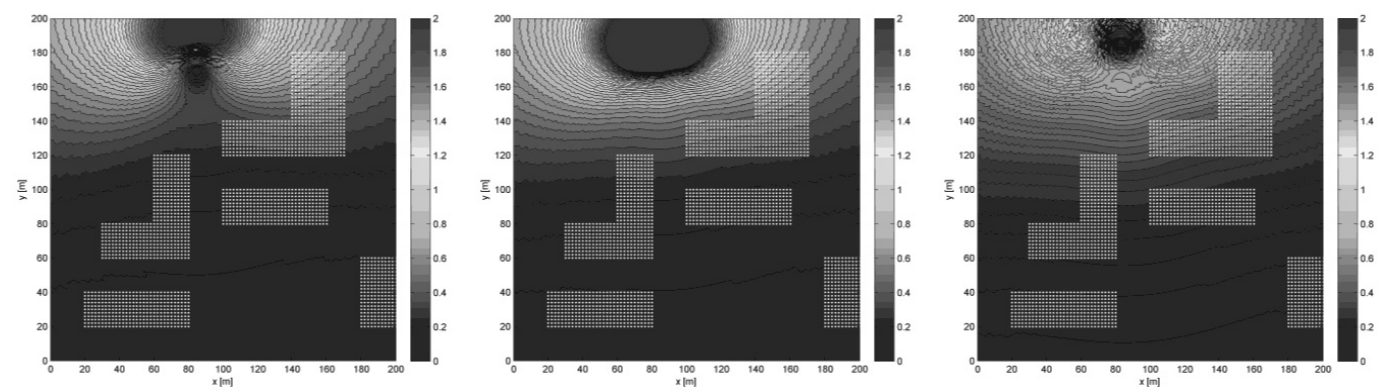
a. $\mathrm{z}=0 \mathrm{~m}$
b. $\mathrm{z}=20 \mathrm{~m}$
c. $\mathrm{z}=40 \mathrm{~m}$

Figure 5. Contour and values of strength of the electromagnetic field in the observed area for the best individual for the $7^{\text {th }}$ case of restricted subarea configuration, antenna 1 , for $0 \mathrm{~m}, 20 \mathrm{~m}$ and $40 \mathrm{~m}$ heights.

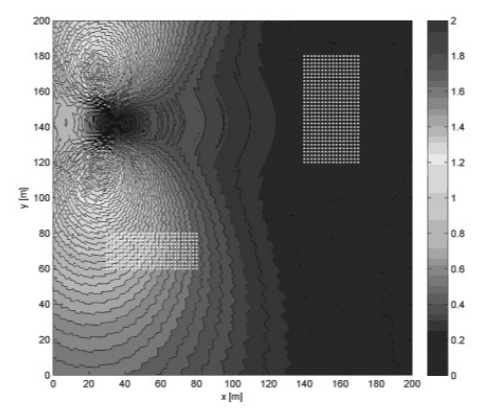

a. $\mathrm{z}=0 \mathrm{~m}$

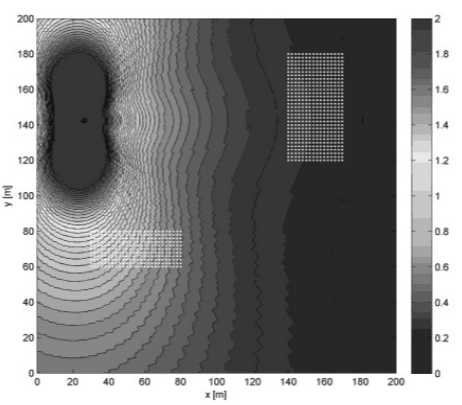

b. $\mathrm{z}=20 \mathrm{~m}$

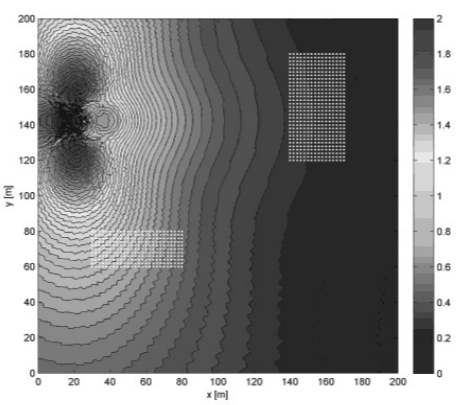

c. $\mathrm{z}=40 \mathrm{~m}$

Figure 6. Contour and values of strength of the electromagnetic field in the observed area for the best individual for the $5^{\text {th }}$ case of restricted subarea configuration, antenna 2 , for $0 \mathrm{~m}, 20 \mathrm{~m}$ and $40 \mathrm{~m}$ heights.

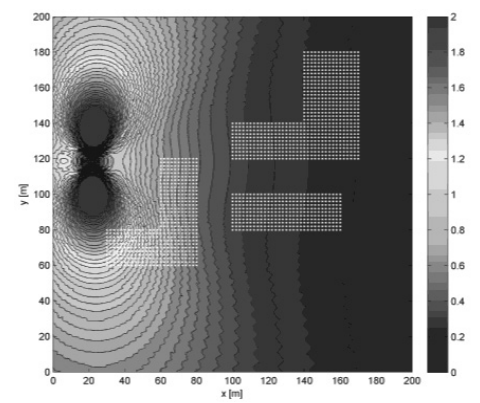

a. $\mathrm{z}=0 \mathrm{~m}$

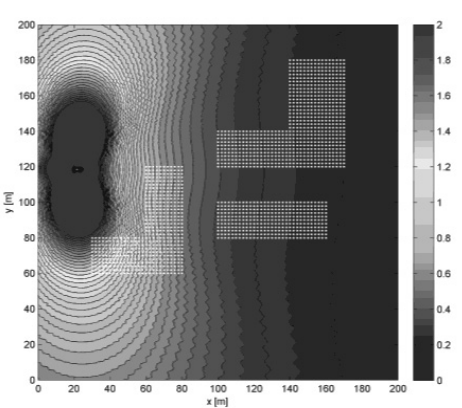

b. $\mathrm{z}=20 \mathrm{~m}$

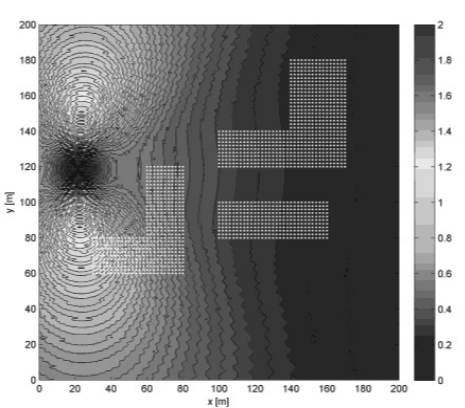

c. $\mathrm{z}=40 \mathrm{~m}$

Figure 7. Contour and values of strength of the electromagnetic field in the observed area for the best individual for the $6^{\text {th }}$ case of restricted subarea configuration, antenna 2, for $0 \mathrm{~m}, 20 \mathrm{~m}$ and $40 \mathrm{~m}$ heights. 


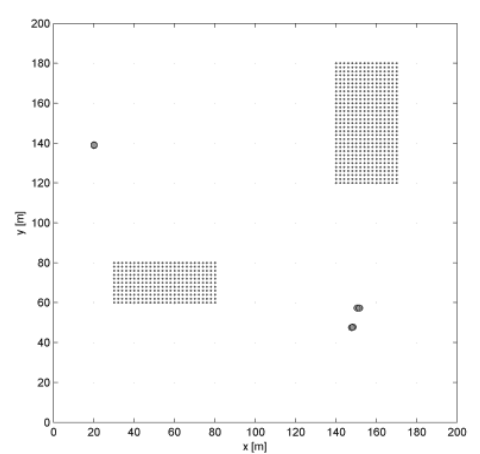

a. the $5^{\text {th }}$ case

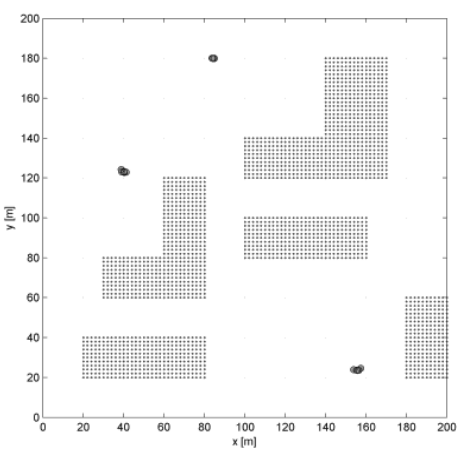

b. the $7^{\text {th }}$ case

Figure 8. Examples of valid transmitter positions from the last generation for the $5^{\text {th }}$ and the $7^{\text {th }}$ cases of restricted subarea configuration for antenna 1.

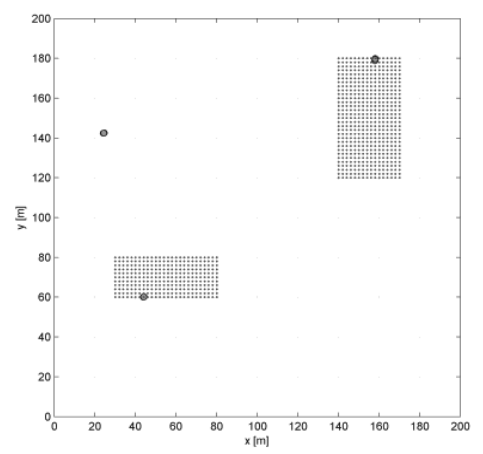

a. the $5^{\text {th }}$ case

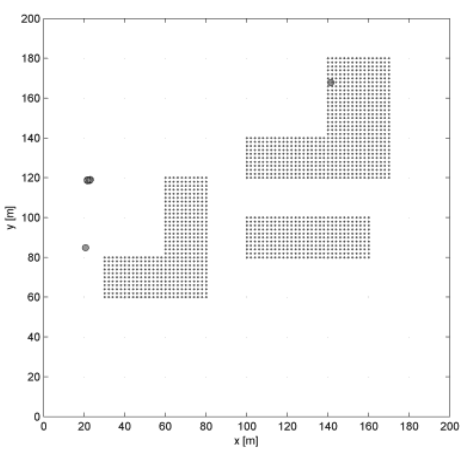

b. the $6^{\text {th }}$ case

Figure 9. Examples of valid transmitter positions from the last generation for the $5^{\text {th }}$ and the $6^{\text {th }}$ cases of restricted subarea configuration for antenna 2.

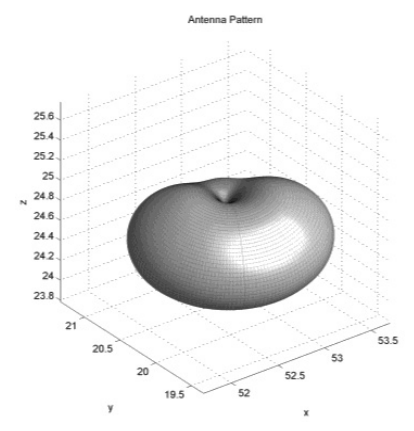

a. $1^{\text {st }}$ case

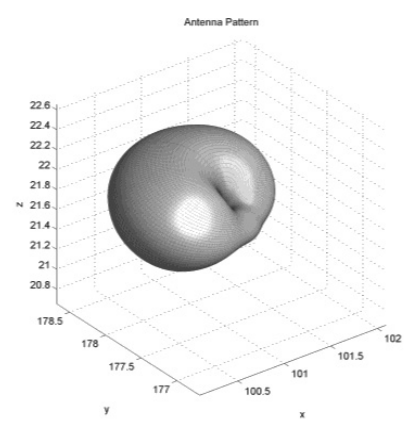

b. $2^{\text {nd }}$ case

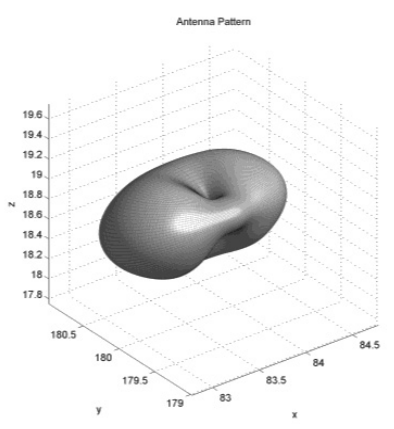

c. $7^{\text {th }}$ case

Figure 10. Spatial radiation diagram of antenna 1 radiation for $1^{\text {st }}, 2^{\text {nd }}$ and $7^{\text {th }}$ case.

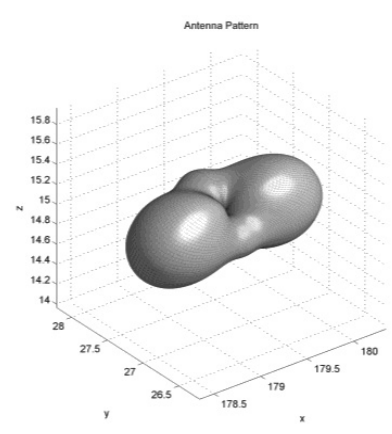

a. $1^{\text {st }}$ case

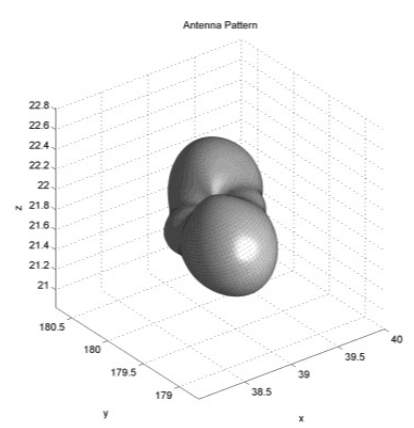

b. $3^{r d}$ case

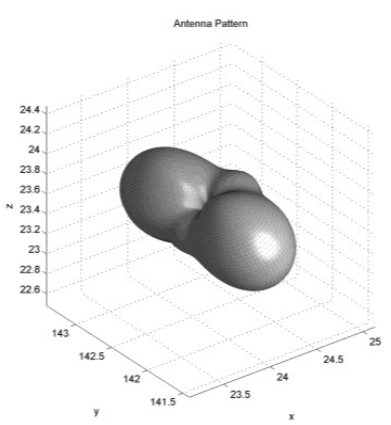

c. $5^{\text {th }}$ case

Figure 11. Spatial radiation diagram of antenna 2 radiation for the $1^{s t}, 3^{\text {rd }}$ and $5^{\text {th }}$ cases. 


\section{Conclusion}

Based upon previous investigations $[6,7,8,9]$ and here obtained results for two antenna types and various terrain configurations, it can be concluded that the method is promising and can give satisfactory results. Although the method is quite computing demanding comparing to 2D problems $[6,7,8]$, it is still quite acceptable for ordinary and inexpensive equipment (office PC). The main reason for excessive computing requirements is the number of points in the $3 \mathrm{D}$ for which electromagnetic field strength has to be calculated. Aside from that, the method is simple, straightforward and independent of terrain configuration or antenna type. Additional method benefit are "almost" optimal solutions which give certain freedom in antenna placement and avoidance of prohibited placement positions for the antenna. Future investigation will include more than one antenna, where antennas can be of different types, few antennas can be positioned in the same point in 3D (on the same support pole) etc.

\section{References}

[1] E. Alba, J. F. ChicAno, Evolutionary Algorithms in Telecommunications, http://neo.lcc.uma. es/staff/francis/pdf/melecon06.pdf, Accessed: 23.11.2011.

[2] E. ALBA, Evolutionary Algorithms for Optimal Placement of Antennae in Radio Network Design, http: //www. lcc.uma.es/ eat/pdf/ nidisc2004.pdf, Accessed: 23.11.2011.

[3] E. Alba, G. Molina, F. Chicano, Optimal Placement of Antennae using Metaheuristics,http://neo.lcc.uma.es/staff/francis/ pdf/nma06.pdf, Accessed: 23.11.2011.

[4] S. P. Mendes, J. A. G. Pulido, M. A. V. RoDRIGUEZ, M. D. J. Simon, J. M. S. PEREZ, A Differential Evolution Based Algorithm to Optimize the Radio Network Design Problem, http://www. icsi. berkeley. edu/ storn/ deb06.pdf, Accessed: 23.11.2011.

[5] A. J. Nebro, E. Alba, G. Molina, F. Chicano, F. LUNA, J. J. DURILlO, Optimal Antenna Placement Using a New Multi-Objective CHC Algorithm, http://neo.lcc.uma.es/staff/guillermo/ index_files/files/MOCHC.pdf, Accessed: 23.11.2011.
[6] T. Rolich, D. Grundler, Minimizing Environmental Electromagnetic Field Pollution Adjusting Transmitter Parameters Using Genetic Algorithm, 2009 IEEE Congress on Evolutionary Computation, Trondheim, Norway, pp. 881-887, (2009).

[7] T. Rolich, D. GRUndLER, Managing Electromagnetic Field Pollution Using Genetic Algorithm, 32nd International Convention on Information and Communication Technology, Electronics and Microelectronics - MIPRO 2009, Opatija, Croatia, pp. 227-232, (2009).

[8] T. Rolich, D. GRUndLER, Determining optimal power, location and direction of transmitters using a genetic algorithm, $33^{\text {rd }}$ International Convention on Information and Communication Technology, Electronics and Microelectronics - MIPRO 2010, Opatija, Croatia, pp. 161-166, (2010).

[9] T. Rolich, D. GRUNDLER, Reduction of electromagnetic field pollution in 3D space using a genetic algorithm, 2010 IEEE World Congress on Computational Intelligence, Barcelona, Spain, pp. 3945-3949, (2010).

[10] CEI/IEC 61566: 1997 International Standard: Measurement of exposure to radiofrequency electromagnetic fields - Field strength in the frequency range $100 \mathrm{kHz}$ to $1 \mathrm{GHz}, 1997$.

[11] Kathrein Scala Division - professional antenna and filter products for broadcast, land mobile and wireless communication applications, Available: http: //www . kathrein-scala.com/, 2011.

[12] The MathWorks - MATLAB and Simulink for Technical Computing, Available:

http://www . mathworks. com/, 2011.

[13] F. MiKAS, P. PECHAC, The 3D Approximation of Antenna Radiation Patterns, The Institute of Electrical Engineers, The IEE, Michael Faraday House, Six Hill Way, 2003.

[14] Genetic Algorithm and Direct Search Toolbox User's Guide, Version 2, The MathWorks, Inc., 2006.

[15] J. E. BAKER, Reducing Bias and Inefficiency in the Selection Algorithm, Proceedings of the Second International Conference on Genetic Algorithms and their Application, pp. 14-21, 1987.

[16] T. B̈̈CK, Evolutionary Algorithms in Theory and Practice: Evolution Strategies, Evolutionary Programming, Genetic Algorithms, Oxford University Press, 1996.

[17] D. E. GolDBERG, Genetic Algorithm in Search, Optimization and Machine Learning, Addison-Wesley, Reading MA, 1989.

Received: December, 2011 Accepted: January, 2012 


\author{
Contact addresses: \\ Tomislav Rolich \\ Faculty of Textile Technology \\ University of Zagreb, Croatia \\ e-mail: tomislav.rolich@ttf.hr \\ Darko Grundler \\ Faculty of Textile Technology \\ University of Zagreb, Croatia \\ e-mail: darko.grundler@ttf.hr
}

TOMISLAV ROLICH was born on $22^{\text {nd }}$ April 1971 in Zagreb. He graduated from the Faculty of Electrical Engineering and Computer Science, University of Zagreb in 1995, under the mentorship of Prof. Neven Mijat.

In January 1995, during the study, he got a job in the Technical School "Ruđer Bošković", first as an associate and later as a teacher. In October 1998 he got a job at the Faculty of Textile Technology, University of Zagreb as a junior assistant for the courses: Information, Computing and Applied Computing. At the same time he enrolled in postgraduate studies at the Faculty of Electrical Engineering and Computer Science, University of Zagreb.

In November 2001, he got the Master's degree from the Faculty of Electrical Engineering and Computer Science, University of Zagreb, with the theme "Evaluation of the Application of Evolutionary Algorithms in Achieving Optimal Control" under the mentorship of Prof. Darko Grundler. In April 2005 he got the Ph.D. degree from the Faculty of Electrical Engineering and Computer Science, University of Zagreb, with the theme "Searching the Space of Aesthetic Evaluation for Matching Weave and Color in Fabrics Design" under the mentorship of Prof. Darko Grundler.

His research activity is in technical sciences, computer engineering and artificial intelligence and his area of special research interest is evolutionary algorithms, neural networks and fuzzy logic. His current position is that of an associated professor at the Faculty of Textile Technology, University of Zagreb. He has published 39 papers, delivered 15 presentations at international conferences; he is co-author of several university handbooks and two university textbooks.

DARKO GRUNDLER was born and lived in Zagreb (Trešnjevka) until the age of 25 . In 1973 started to work in Kutina as a secondary school teacher. From 1976 he was employed in Kutina in the company SELK on various positions, mainly as technical manager. From 1990 he was a lecturer, assistant professor and professor at the University of Zagreb, Faculty of Textile Technology. Among other things, his professional experience includes: electronic watches assembly, optoelectronics assembly, single board computers design and application, microprocessor based system design and application, CAM, PC based industrial control, genetic algorithms in general and specially applied to process control. He is the author or coauthor of more than thirty books and textbooks (one awarded) in the field of microprocessors, personal computers, MATLAB, evolutionary computation, etc. Field of recent interest and research: genetic algorithms applied to process control and textile design. 
